\title{
Ensayo "machirulo"1. Hacia la comunicación del vínculo, del cuidado y de los afectos*
}

\author{
Ómar Rincón Rodríguez
}

Recibido: 3 de octubre de 2019 • Aprobado: 11 de noviembre de 2019

\section{Resumen}

En este ensayo "machirulo" - mansplaining, intentando ser discursivamente correcto-, se parte de la vitalidad política, cultural y comunicativa del movimiento feminista como propuesta de que otro mundo-economía-sociedadcultura es posible, para luego reparar en que se debe intentar hacer una comunicación feminista desde lo narrativo, la estética y los formatos, y termina con la perplejidad de cómo hacer posible un feminismo en perspectiva de les jóvenes.

Palabras calave: comunicación, estéticas, feminismo, formatos, jóvenes, narrativas.

1 Machirulo es una expresión de uso popular en Argentina, adaptado por el movimiento feminista para referirse a un hombre machista en posición de poder que se se hizo viral a partir de un tweet de Cristina Fernández en respuesta a Macri, gente a la que la vida se les va en machismos neoliberales e hipocresías de mercado. Yo lo retomo para nombrar a los que nos creemos progres, hippies, onegeros, académicos y feministas, y al final somos solo machistas escondidos detrás de una retórica. Me parece que la palabra machirulo nombra al macho que no podemos expulsar de nuestro cuerpo y mente.

* Ensayo, porque es la forma que creo que tienen de contar las mujeres: ellas son auténticas por eso no citan, no repiten teorías, no hacen lo que es obvio hacer: eso es para los hombres. Ensayo es intentar pensar con la cabeza propia, el cuerpo propio, la vida propia: es hacer la vida, es inspirarse en las mujeres. Citar como: Rincón Rodríguez, Ó. (2020). Ensayo "machirulo". Hacia la comunicación del vínculo, del cuidado y de los afectos. Análisis, 52(96), 151-163. Dol: https://doi.org/10.15332/21459169/5341

** Doctor en Ciencias Humanas y Sociales, Universidad Nacional de Colombia. Master of Arts, State University of New York, Albany (Nueva York). Comunicador Social-Periodista, Universidad Javeriana (Colombia). Profesor asociado, Centro de Estudios en Periodismo (CEPER), Universidad de los Andes. Correo: orincon@uniandes.edu.Co. ORCID: https://orcid. org/0000-0002-8690-2253 


\section{"Machirulo" essay. Towards the communication of the bond, care and affection}

Ómar Rincón Rodríguez

\section{A bstract}

This "machirulo" - mansplaining, attempting to be discursively correct - essay, is based on the political, cultural and communicative vitality of the feminist movement as a proposal that another world-economy-society-culture is possible, to then notice that an attempt should be made to make feminist communication from the narrative, aesthetics and formats, and finishes with the perplexity of how to make feminism possible in the perspective of young people.

Keywords: communication, aesthetics, feminism, formats, youth, narratives. 


\section{Essai "machirulo". Vers la communication du lien, du soin et des affects}

Ómar Rincón Rodríguez

\section{Résumé}

Cet essai mansplaining — si l'on veut rester discursivement correct - reconnaît la vitalité politique, culturelle et communicative du mouvement féministe et sa proposition d'un autre monde-économie-société-culture. Puis on remarque la nécessité d'une communication féministe qui parte du narratif et l'esthétique et l'on se demande, enfin, comment animer un féminisme adressé aux jeunes.

Mots clés: communication, esthétiques, féminisme, jeunes, narratives. 


\section{Introducción}

Soy hombre y estoy definido por el mandato de masculinidad (Segato, 2018), ese que me hace parte de la jauría masculina que, para quedar bien con sus pares, maltrata de palabra, obra, símbolo y omisión; ese que hace mansplaining para explicar a las mujeres su situación, lo que ellas ya saben en cuerpo; ese que hace chistes sobre las mujeres como manera de liberación de su miedo a las mujeres; ese machirulo u hombre "progre", de izquierda, hippie, académico u oenegero que se siente "compañero" de las mujeres y feminista de discurso mientras sus modos de actuar develan un macho soberbio y asqueroso.

No hablaré de feminismo, menos de mujeres, solo de comunicación. Voy a escribir de mujeres y comunicación. Y lo hago porque enuncio desde la comunicación, o donde se evidencia esos modos mainstreaming de producir percepciones y emociones sobre las mujeres y los feminismos; esos modos de (in)visibilizar y (des)representar a las mujeres en los relatos mediáticos; esas narrativas higiénicas y asépticas de los géneros periodísticos y formatos televisivos que dicen no tener ideología ni machismos. Desde ahí me asumo para sugerir que la comunicación debe ser femenina, pero no por hablar de feminismos o de temas supuestamente mujeriles que decimos los hombres como la salud, la familia, la sexualidad, la intimidad; tampoco por mejorar la representación de cuerpos y rostros femeninos en los relatos mediáticos. La propuesta es asumir que lo femenino es otra manera de narrar, otra estética, otro modo de contar e imaginar la comunicación y los relatos del mundo. Que cómo es, no sé, pero algo se puede vislumbrar en el cine de la argentina Lucrecia Martel (La Ciénaga, La niña santa, La mujer sin cabeza, Zama) o la peruana Claudia Llosa (Madeinusa y La teta asustada) o la colombiana Laura Mora (Matar a Jesús).

\section{Antes del fin, existen las mujeres}

El fin se veía venir; llegaba en forma de guerras y capitalismo, en extractivismo de todo: naturaleza, historias, vidas, saberes. Pero las mujeres, sin matar a nadie, revolucionaron el mundo, cambiaron el mar que habitamos y abrieron la sociedad a su pluralidad de raza, clases, orientaciones sexuales, culturas (dicen que eso contó Agnes Heller, pero no tengo la cita). Las mujeres en siglo xx nos dijeron que el mundo no era blanco, macho y occidental, sino también femenino, oriental, afro, indígena, gay y de muchas más formas. Y el hombre tuvo miedo, pero dijo que sí de dientes para afuera, que comprendía. Y ahora cuando las mujeres expresan la utopía posible de otro mundo: uno de afectos, de vínculos, de cuidados, de solidaridades, de regenerar y de sostenibilidad..., ese macho aparece y dice que "las mujeres son el comunismo", que han llegado para acabar con el hombre, la familia, la patria, Dios y la propiedad privada (o sea, lo que somos). Y es verdad, han llegado con la fuerza política y de calle y de territorio y de ideas y de saberes y de cuerpos para cambiar el mundo. $Y$ ese miedo se traduce en autoritarismos vandálicos al estilo Trump, Putin, Bolsonaro, 
Uribe (todas las ideologías unidas al capitalismo extractivista en el miedo a las mujeres). Pero las mujeres están aquí y van luchando y van ganando, porque tienen qué decir y proponer (una economía del cuidado); ponen el cuerpo en la calle, en lo público, en la justicia, en los medios y las redes (el "me too", el "ni una menos", el "con mi cuerpo no se meta"); tienen otra manera de comunicar en clave más solidaria y menos competitiva (intuyo en sus modos de narrar).

\section{Las luchas feministas}

Las luchas feministas han contribuido a desafiar estructuras patriarcales mediante agendas innovadoras que han resultado en el reconocimiento y ejercicio de derechos, a través de márgenes de acción cada vez más influyentes. Sin embargo, el auge y la importancia del feminismo en la actualidad contrastan con los desafíos que enfrenta, por ejemplo, de cara a ampliar la participación política de las mujeres, así como erradicar todo tipo de violencia de género. Por lo tanto, urge identificar caminos, ideas y enfoques para dinamizar los valores transformadores del feminismo. Eso leo en el proyecto fe(s)minismos [@fesminismos, ¡El futuro es feminista!]. Y cuenta que la agenda urgente para hacer la transformación social y política y cultural desde y en el feminismo implica lo siguiente:

- Asumir al feminismo en diversidad, pluralidad, interculturalidad: o sea, hay feminismos. Como lo expresa Claudia Corol (2016):

[Reconocer y vincular] la irrupción en la política de colectivas de acción, pensamiento, sentimientos, sueños, que asumimos el feminismo como una propuesta quedesafía a las múltiples opresiones producidas por el capitalismo colonial y patriarcal (a) los feminismos indígenas, campesinos, barriales, de trabajadoras de doble y triple jornada. Feminismos de sujetas no sujetadas, que respondemos colectivamente a los desafíos de la sobrevivencia y vamos haciendo realidad la propuesta: "si tocan a una, tocan a todas". (p. 142)

- La necesidad de desafiar la injusta y desigual institucionalización de estructuras de poder capitalistas y patriarcales en las relaciones de género en la economía, la sociedad y la política. Tomando en cuenta la profundidad y la sistematicidad de estas desigualdades, las luchas feministas deben ser abordadas desde perspectivas interseccionales que alberguen criterios de clase, etnicidad, orientación sexual, entre otros.

- Trabajar desde el feminismo político que proponga un otro mundo, estructuralmente y orgánicamente, diferente e incluyente de todas las posibilidades de existir que tiene como ejes (i) una economía del cuidado y sostenible que promueva la vida, la solidaridad e interdependencia entre todos sujetos, colectivos y mundos diversos de saber; (ii) un activismo 
regenerativo ante la proliferación de antifeminismos y poderes autoritarios, ya que hay que actuar porque el panorama político y social se está volviendo cada vez más represivo, xenófobo, intolerante, extremista y patriarcal con las diversidades $\mathrm{y}$, por lo tanto, desarrollar nuevas tácticas y estrategias para contrarrestar estas tendencias; (iii) derecho a la migración y a la movilidad desde una perspectiva feminista, para que las feministas del norte global en diálogo con las feministas del sur global desarrollen una conciencia de la relación entre patriarcado, racismo y clasismo, cuestionen sus privilegios y posicionen en la agenda pública el trabajo de cuidados invisibilizado de las migrantes.

- Se acabó el tiempo del mainsplanning y el oenegismo internacional. Hay propuestas de radicalizar el discurso, la acción, la emoción y los cuerpos para ir más allá del enfoque de género hacia un enfoque feminista. Por eso, hablar de género es tibio, es un tema burocrático de cumplir con cuotas y altamente institucionalizado, cuando el feminismo es desmontar estructuras desiguales desde sus bases, incomodando a las estructuras patriarcales y de clase, y de raza, y de sexo.

- Hay movida y movimiento feminista. En Chile las tomas feministas en más de una docena de universidades exigen la erradicación de violencia machista y la discriminación y tienen como objetivo una reforma educativa con perspectiva feminista. En Bolivia, la presencia de mujeres en instancias de poder por parte de mujeres ha brindado una especie de sentido de cambio. En Uruguay existe una emergencia discursiva. En Argentina el "ni una menos" y los pañuelos verdes han puesto a la política en el centro de la democracia.

Y hay mucho más para soñar y creer en el cambio, pero sigue siendo alarmante que las mujeres se hayan transformado tanto y los hombres tan poco; que la política feminista esté en más cuerpos jóvenes y disidentes y que el sistema político cambie tan poco; que todavía persistan brechas y desigualdades tan grandes en lo económico entre mujeres y hombres; que los estereotipos sigan marcando las narrativas mediáticas y de la coolture. Discursivamente, andamos en los juegos de lenguaje entre un proyecto político (el feminista), una construcción cultural (mujer), una identidad sexual (diverso). Y estos juegos del lenguaje no los hemos entendido los medios de comunicación, los periodistas y la cultura pop. Por ahora, el feminismo mediático se quedó en que es un asunto de lenguaje y no de derechos, de poner mujeres en pantalla sin cambiar el libreto con que contamos. El feminismo mediático es más un acto de caridad cristiana de inclusión para sentirnos no machistas. No reconocemos que le tenemos miedo a las mujeres. Ni tampoco que la puesta activa y sin vergüenza del mandato de mascunilidad expresa y devela una escena de celos, porque ellas se tomaron el espacio público (están donde nosotros estábamos) y porque ellos asumieron la autonomía de sus cuerpos (hacen lo que desean con sus deseos y cuerpos, y eso lo decidíamos nosotros). 


\section{Feminismos jóvenes}

Esas formas de la comunicación mainstreaming representan a las feministas como unas luchadoras radicales contra los hombres, agresivas, sin femeneidad e histéricas, que no quieren darse cuenta de cómo hoy las mujeres están en mejor posición que antes. Y este modo de la comunicacion rompe el vínculo con las y los jóvenes que creen que el feminismo es un asunto de no les toca porque ya están liberades. Las y los jóvenes se saben feministas, pero no en las formas que el feminismo blanco, occidental, académico y mediático les propone. Y llegar a producir un feminismo joven es una prioridad política del movimiento.

En 1996, Guindon² en Canadá se preguntó por qué el feminismo no atrae a las jóvenes y, después de conversar con muchas, llegó a la conclusión de que la oposición al feminismo es un tema importante en el discurso de las mujeres jóvenes (y lo sigue siendo en las jóvenes de países como Colombia). Asimismo, concluyó que hay cinco razones para explicar por qué las jóvenes no están de acuerdo con el feminismo:

- La ignorancia del feminismo: "el pensamiento feminista denuncia la opresión individual y colectiva de las mujeres; en la era del individualismo, las mujeres jóvenes no se adhieren a esta idea de experiencia común". Eso sí, están de acuerdo con la idea de igualdad, independencia y autonomía.

- Para ser feminista, uno debe sentirse agraviado (y a ellas no les gusta sentirse así). Es más, le temen a ser "radicales, exageradas y agresivas", y a estar demasiado politizadas, ya que ellas no creen en la política.

- El feminismo es para otra generación. Ellas perciben que el movimiento feminista parte de que las mujeres son inferiores, y ellas se sienten iguales; por eso, pregonan que lo que hay que hacer es rebelarse contra las diversas formas de opresión como el racismo, la pobreza, el medio ambiente y las injusticias.

- El feminismo es igual a radicalismo y reclamos (y a ellas no les gusta esa actitud de lucha). Y es que ahora "la diferencia con el sexismo es que es más sutil, más difícil de percibir", y que el sexismo es un problema de la sociedad en el que todos debemos implicarnos.

- El feminismo es exclusivo de las mujeres (mientras ellas creen que debe involucra a los hombres como compañeros).

Esto ocurría en los años 90, en un país adelantado, pero muchas de estas posturas siguen estando presentes en las y los jóvenes del siglo xxi. Por ejemplo, hay jóvenes mujeres que rechazan al feminismo y llaman "feminzasis" a las que

2 Geneviève Guindon, Département de sociologie de l'Université de Montréal, janvier 1996. Colloque La jeunesse au carrefour: quelles perspectives pour l'avenir?, Congrès de l'Association canadienne-française pour l'avancement des sciences (ACFAS) à Trois-Rivières, les 12 et 13 mai 1997. 
militan duro, pero no se dan cuenta de que "esa" libertad de cuerpo y palabra es posible por las luchas feministas. Si se quisiera promover un feminismo para las y los jóvenes hay que seguir aceptando estos argumentos y construir un movimiento que tenga en cuenta lo ganado en la lucha feminista para en agendas, activismos y otras comunicaciones intervenir estas posiciones cómodas de lo sujetos que hcen el siglo xxi. Hoy, las y los jóvenes tienen sus propios estilos de feminismos. Para querer cambiar el modo que hemos venido siendo, la comunicación debe partir de esta percepción para poder vincular a más jóvenes al movimiento feminista.

La esperanza llega porque también aparece una nueva tendencia de jóvenes que quieren ser radicales, agresivas/os y exageradas/os en torno a los asuntos de las mujeres, pero también del medio ambiente y las corporalidades disidentes. Las y los jóvenes ya han tomado la bandera y son el motor, al menos en Argentina y Chile, de muchas de las luchas y las sororidades; lo bueno del movimiento es que une diversidades políticas, de cuerpos y generacionales, entre otras. Pero también son mediatizados como jóvenes que vienen a destruir la sociedad, que atentan contra el decoro y las buenas costumbres y que casi son unas vándalas públicas. A pesar de los medios y el conservadurismo político, estas jóvenes están aquí y están en modo de lucha tomándose las redes, las calles, la vida política.

Esto está pasando porque, "a pesar de la ofensiva conservadora que conmueve este tiempo, arrasando conquistas de los pueblos, contagiando cólera y rabia en los corazones, hay un aquelarre subterráneo, un movimiento de conciencia histórica que crece, se 'encuerpa' desde la memoria, y cambia - nos cambia - la vida cotidiana" (Korol, 2016, p. 146). Y son los feminismos populares en los que:

[...] hay poca distancia entre las palabras y los actos, y las prácticas van caminando más rápido que las teorías. Tenemos la fortaleza de nuestro activismo y la debilidad de los procesos de sistematización de las prácticas y de sus aprendizajes, que quedan siempre relegados por atender "urgencias" que nos "matan". Porque en tiempos conservadores crece la violencia contra las mujeres, crecen los femicidios y crecen las emergencias que vuelven más vulnerables nuestras vidas. Porque además los Estados no cumplen con las tareas de cuidados que deberían asumir. (Kotol, 2016, p. 146)

González-Sánchez $(2009)^{3}$, quien se define como "feminista, mujer biológica y cultural, heterosexual de baja intensidad", cuenta que "cada generación coloca su propia marca al interpretar y vivir el feminismo". Ya Virginia Woolf nos hablaba sobre la condición femenina y la enajenación de la mujer en la sociedad en ese bello relato "Una Habitación Propia" y nos proponía que la mujer debía contar con un cuarto propio y 500 libras pero que además debería encontrar su propia voz para narrarse. Woolf cuenta que al sacar del estante la novela La Aventura

3 ¿Existe un proyecto feminista para la transformación social? Jóvenes, diversidades y proyecto feminista. Encuentros y desencuentros. III Seminario Virtual Repem/Jovfem, 17 al 29 de junio de 2009, Bogotá. Sistematización realizada por Gabriele Merz. 
de la Vida escrita por Mary Carmichael leyó en una página abierta al azar: "A Chloe le gustaba Olivia..." y sigue alerta para encontrar el suceso, porque como ella misma lo expresa "porque si a Chloe le gusta Olivia y Mary Carmichael sabe expresarlo, encenderá una antorcha en esta gran cámara donde nadie ha penetrado todavía...". Y agrega que "autonomía individual, independencia económica, capacidad de vernos y narrarnos a nosotras mismas... como dice el bolero, hoy como ayer son construcciones del sujeto mujer". Y se pregunta si "¿Acaso son tan anacrónicas que no interesan al movimiento feminista de jóvenes?".

González-Sánchez (2009) propone lo siguiente:

Hay que hablar de feminismos ya que al ser conscientes de las diferencias y tenerlas en cuenta se hace un feminismo que tenga sentido para las jóvenes, no encerrado en un contexto nacional sino que esté atento a las repercusiones de la vida cotidiana en las dinámicas globales. La búsqueda política y de acción cotidiana es cómo incorporar la heterogeneidad sin perder la identidad política que se base en una plataforma y un proyecto común.

Tal vez asumiendo que lo femenino son muchas identidades fluidas, a las jóvenes les parezca más posible ser feministas.

El feminismo hackea al capitalismo sin destruirlo y permite imaginar otros modos de estar y ser sociedad, que están demostrando que se puede activar desde los cuerpos, desde las autonomías colectivas, desde la economía de los vínculos, desde la apuesta por el cuidado:

Una politicidad en clave femenina es —no por esencia sino por experiencia histórica acumulada-, en primer lugar una política del arraigo espacial y comunitario; no es utópica sino tópica; pragmática y orientada por las contingencias y no principista en su moralidad; próxima y no burocrática; investida en el proceso más que en el producto; y sobre todo solucionadora de problemas y preservadora de la vida en lo cotidiano [...] un proyecto histórico de los vínculos [que] insta a la reciprocidad, que produce comunidad. (Segato, 2018, pp. 15-16)

Desde aquí es posible imaginar una comunicación inscrita en lo comunal, en lo pragmático y coyuntural, de cercanía y colaborativa, que soluciona asuntos cotidianos y promueve la economía de los vínculos. Las mujeres ya nos están mostrado que otro mundo y otra comunicación es posible con su presencia en las calles, en la política, en las redes, en los cuerpos; comunicativamente, el movimiento feminista es tendencia de sentidos, es digital, es activista, es irreverente y juega a politizar desde lo contracultural. Tal vez, ahí encontremos las experiencias y prácticas para salir del modelo de desarrollo en el que el mercado nos quiere aprisionar. 


\section{Comunicación feminista}

En este contexto, el feminismo mediático debe, además de provocar el lenguaje incluyente, la expansión de voces de mujeres, la diversificación de las representaciones femeninas, luchar por narrar y contar en sus propias estéticas, narrativas y formatos: no es solo un asunto de contenidos; es sobre todo de modos, tonos y formas del relato. Nos hemos acostumbrado tanto a que narramos como Occidente, blanco y masculino que no podemos imaginar que podemos hacerlo de otras maneras, tonos, dramaturgías, estéticas. Hace tiempos (2009) y desde mi enunciación desde y en la comunicación, y como machirulo, y después de haber leído todos los textos de 16 periodistas mujeres que escribían poniendo en escena la perspectiva de género en el periodismo (Santoro, 2009), mansplannié lo siguiente:

Habitamos los tiempos de las crisis o las transformaciones. jLas cosas han salido mal! La sociedad de mercado no soluciona lo social, el capital es cada vez más injusto, los políticos juegan a enriquecerse. ¡Todo mal! El periodismo es un oficio humanista que ni cuenta ni encanta, los hombres parecemos un mal invento, el pensar huye en el pensamiento eslogan y light. $¡$ Hemos llegado a la democracia cínica! Entonces, ¿dónde está la posibilidad, la esperanza, la tendencia para un mundo mejor? En los otros sujetos de la historia y el futuro, uno fundamental las mujeres. Y para pensar desde ellas debemos comenzar a conocer, sentir y hacer más de lo que ellas hacen y producen. A eso es a lo que llamamos "perspectiva de género" que es una filosofía para comprender, narrar y transformar la vida. [...] La filosofía de "la perspectiva de género" no consiste en celebrar "el mujererismo" (¡que no estaría nada mal!), sino en comprender, narrar y producir sentidos desde otros modos, otras voces, otros tonos, otros sujetos. Cuando "la perspectiva de género" se pone en práctica en el periodismo, aparecen otros modos de contar, otros encantos para la realidad, otros puntos de vista para comprender la vida. Y es que "la perspectiva de género" actúa y transforma el periodismo, la comunicación social y las culturas mediáticas. Hacer periodismo con enfoque de género, no es hablar de mujeres, ni de supuestos temas de mujeres como salud, educación, moda, hogar, belleza... significa asumir un compromiso político con la visibilidad y reconocimiento de las mujeres, que han estado históricamente ocultadas o sub-representadas por los medios de comunicación. (pp. 5-7)

Y mansplannié el siguiente decálogo para hacer un "periodismo en perspectiva de género":

1. Una opción política para develar la posición de desigualdad y subordinación de las mujeres en relación a los hombres.

2. Otra agenda, otra esfera pública. El privilegiar otros valores como preservar, cuidar, solidaridad, colaboración, diálogo. Esto 
significa reivindicar aspectos específicos de la condición de las mujeres y sus circunstancias materiales inmediatas en las que viven.

3. Un radar para descubrir modos instalados de discriminación. Un enfoque que contempla cómo mujeres y varones son afectados en forma diferenciada por un mismo hecho o realidad. Se debe tener conciencia sobre el tipo de imágenes, metáforas, referentes que se usan para contar la realidad.

4. Una estética vivencial. Producir un periodismo más colaborativo, más de tejido, más experiencial, más dramatúrgico.

5. Una narrativa testimonial. Una iniciativa para contar desde lo subjetivo, en primera persona y contando con la vida cotidiana.

6. Se vale lo emocional. Hay que buscar la expresión afectiva, contar desde y con la cultura emocional. Se vale la bronca, la rabia, lo personal.

7. Un lenguaje cuidadoso y expresivo. El uso de un lenguaje inclusivo y no sexista; pero, a su vez, la presencia de un lenguaje cotidiano, del lenguaje de la vida.

8. Fuentes que comprendan más que opinen. Trabajar con fuentes especializadas, ojalá mujeres, con sujetos que cuentan desde su experiencia de vida y con analistas que tengan en cuenta la posición de las mujeres y otras sensibilidades (étnicas, sexuales, ambientales) frente a las agendas de actualidad.

9. La perspectiva para contar siempre está en otra parte. Enfatizar otros puntos de vista a los hechos, reivindicar otras identidades, desplazar la perspectiva de los modos mediacéntricos y podercéntricos hacia otros modos de comprender y explicar, hacia otras entradas a los hechos.

10. Periodismo de posibilidad. Periodismo que siempre plantea soluciones, alternativas, búsquedas. (pp. 7-8)

Y sigo creyendo en es otro periodismo, en otros enfoques, otros formatos, otras estéticas: uno muy político, militante, activista. A ese libro lo titulamos Sin nosotras se les acaba la fiesta, porque esa fue la síntesis de las mujeres incluidas en los relatos: que son ellas las que producen y hacen la vida en el territorio, en lo cotidiano, en lo práctico: ellas que no tienen tiempo que perder hacen de esas experiencias de vida una fiesta, un carnaval, un celebrar la vida. Y hasta pagan el peaje de los machismos religiosos, políticos, amorosos... con tal de que las dejen celebrar la fiesta de la vida. La vida es una fiesta para duluir el extractivismo hecho de hombres. En esta idea, debemos pasar de un periodismo extractivista hecho por hombres, mercado y consumo, a un periodismo regenerativo, 
solidario y del cuidado hecho por mujeres, indígenas, afros, cuerpos disidentes; un periodismo con cuerpos, afectos, atrevido, seductor, encantador y político... un periodismo que intente narrar en otros modos, otros tonos, otras formas y estéticas del ensayo, el análisis, las crónicas, los reportajes; un periodismo que cuenta historias que cuidan la vida.

$Y$ del periodismo debemos pasar a ganar poder en la vida cotidiana en beneficio del colectivo (Rodríguez, 2008) y romper con el mandato masculino de comunicar una sola historia, la oficial, la creada e impuesta por hombres, porque el peligro de una sola historia es que tanto contamos una sola cosa, una y otra vez, hasta que nos convertimos en eso (Adichie, 2010) y esto roba la dignidad a las mujeres, dificulta su reconocimiento, crea estereotipos. Y es que, en las historias, afirma Adichie (2010), importa "cómo se cuentan, quién las cuenta, cuándo se cuentan, cuántas historias son contadas, son temas que dependen del poder. El poder es la capacidad no solo de contar la historia del otro, sino de hacer que esa sea la historia definitiva" (p. 24), y por eso, "las historias importan", hay que expandir y estallar las historias mediáticas. Hacer comunicación feminista debería significar inflacionar las historias desde y en las estéticas de los otros: producir más historias del mundo en perspectiva feminista, afro, indígena, cuerpos disidentes.

Y desde los feminismos una comunicación debe ser del vínculo, del cuidado, sostenible, regenerativa, afectiva, corporal, festiva, solidaria. Eso debe convertirse en criterios de formato, de estética, de narrativa: no es un asunto de contenidos, es un dispositivo de interpelación en los modos de contar e interpelar: esto transformaría radicalmente la comunicación mediática. ¿Cómo es? Solo las mujeres lo saben y hacen.

Otra vez las mujeres tienen que articular, mientras los hombres seguimos en la hegemonía del capital, el discurso, la política y el extractivismo. La lucha es contra los maniqueísmos; afirmar que somos más que dos: más que hombres y mujeres (pero al que hay que deconstruir y transformar es al hombre desde diversas otredades), más que privados y públicos, más que dos. Los feminismos populares y las rebeldías juveniles interpelan y cuestionan. Y ahí la comunicación tiene mucho que proponer, hacer y activar: una comunicación del cuidado del otro, regenerativa de vida, provocador del vínculo en los/as otros/as y de cuidado con el lenguaje, las prácticas y las historias. Se debe comprender, como dijo la feminista de comienzos del siglo $\mathrm{xx}$, que "si no puedo bailar, no quiero ser parte de esta revolución" (Goldman, 2015, p. 514). Ser contracultural siempre es posible y las mujeres nos indican los modos, las formas, los discursos y los mundos para hacerlo. 


\section{$\mathbf{R}_{\text {eferencias }}$}

Adichie, C. (2010). El Peligro de una sola Historia. Arcadia, 56, 24-25.

Korol, C. (2016). Feminismos populares. Las brujas necesarias en los tiempos de cólera. Revista Nueva Sociedad, 265, 142-152.

Goldman, E. (2015). Si no puedo bailar no quiero ser parte de tu revolución. Buenos Aires: La Mariposa y la Iguana.

Rodríguez, C. (2008). Lo que le vamos quitando a la guerra [medios ciudadanos en contextos de conflicto armado en Colombia]. Bogotá: C3 Fundación Friedrich Ebert.

Segato, R. (2018). Contra-pedagogías de la crueldad. Buenos Aires: Prometeo.

Santoro, S. (2009). Sin nosotras se les acaba la fiesta. Bogotá: FEs C3. 